\title{
Implementing Trauma-Informed Care to Improve the Effectiveness of Pediatric Behavioral Healthcare in an Emergency Department
}

\author{
Jo-Ann Marrs EdD, DNP, FNP-BC ${ }^{\mathbf{1}^{*}}$, PMHNP-BC, Khara Jefferson F.N.P ${ }^{2}$

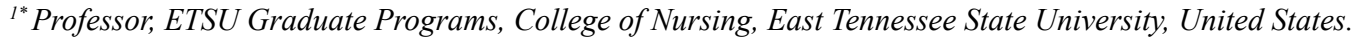 \\ ${ }^{2}$ College of Nursing, Clinical Adjunct Faculty, Frontier Nursing University, United States.
}

\author{
Article Details \\ Article Type: Review Article \\ Received date: $30^{\text {th }}$ November, 2020 \\ Accepted date: $30^{\text {th }}$ December, 2020 \\ Published date: $31^{\text {st }}$ December, 2020
}

*Corresponding Author: Jo-Ann Marrs EdD, DNP, FNP-BC, PMHNP-BC, Professor, ETSU Graduate Programs, College of Nursing, East Tennessee State University, Office 121 Nicks Hall, United States. E-mail:MARRSJ@mail.etsu.edu

Citation: Marrs, Jo-Ann S \& Jefferson, K. (2020). Implementing Trauma-Informed Care to Improve the Effectiveness of Pediatric Behavioral Healthcare in an Emergency Department. J Comp Nurs Res Care 5(2):166. doi: https://doi.org/10.33790/ jenrc1100166.

Copyright: (C2020, This is an open-access article distributed under the terms of the Creative Commons Attribution License 4.0, which permits unrestricted use, distribution, and reproduction in any medium, provided the original author and source are credited.

\begin{abstract}
Background: Suicide rates among young children sky rocketed over the past decade and are one of the leading causes of global death. The cost in productivity, healthcare costs, and human tragedy is inconceivable. Children with suicidal ideation often have trauma histories and could be retraumatized during emergency room visits.

Local Problem: While measurement-based care is the standard in behavioral healthcare, a baseline review of chart audits showed that $95 \%$ of the child's depression was not being evaluated with a screening tool nor $100 \%$ of the parent's anxiety levels. Baseline chart audits revealed noncompliant rates for length of stays, trauma histories, chemical restraints, and recidivism rates. The initial team surveys revealed a lack of knowledge about trauma-informed care (TIC). The aim of this quality improvement initiative was to improve the effectiveness of pediatric behavioral healthcare in the emergency department through the implementation of TIC.
\end{abstract}

Methods: Four plan-do-study-act (PDSA) cycles with four interventions in tandem every two weeks were employed.

Interventions: The core interventions of PHQ-A and HAM-A rating scales, chart audits, and team engagements were analyzed using run charts, aggregate data, and field notes to determine outcomes.

Results: The rating scales showed paradoxical results depending upon the age of the child with less parental anxiety with older children. Chart audit effectiveness rose from $43 \%$ to $64.8 \%$, TIC team increased from $91 \%$ to $100 \%$, and overall effectiveness from $54 \%$ to $65.1 \%$.

Conclusion: This initiative is spreadable and sustainable by using embedded rating scales in electronic medical records, chart audits, and TIC education.

Key words: trauma-informed, emergency department, behavioral health, pediatric, PDSA

\section{Introduction}

Suicide is the second leading cause of global death for those 10-24 years of age $[1,2]$. A United States study shows that the number of children seen in the emergency rooms for suicidal ideation has more than doubled since 2008 with $40 \%$ being between the ages of 5 and 11 years [3]. Locally, this children's emergency department saw more than 600 in 2017 with suicidal ideation [4]. The increased visits make identifying gaps to effective care urgent.

Several baseline gaps were identified from chart audits [5]. Regarding screening $(n=20) 95 \%$ of the children's depression and $(n=20)$
$100 \%$ of parental anxiety as seen in parent surveys and $(n=2)$ parent tracer were not being screened. Only $43 \%$ of the chart audit criteria met acceptable effectiveness scores. In the team survey $(n=10) 42 \%$ and engagement survey $(n=17) 64 \%$ were not satisfied nor knowledgeable that they were using trauma-informed (TIC) evidence-based practice guidelines. Pediatric behavioral healthcare was found to be $54 \%$ effective, and trauma history was recorded on $(n=20) 55 \%$ of children. Because many mental health patients have trauma histories, it is important that they not be retraumatized during the emergency room visit $[3,6]$.

\section{Available Knowledge}

The physical environment and emergency department policies can unintentionally retrigger individuals with trauma histories. The use of TIC has been recognized by the Substance Abuse and Mental Health Services Administration (SAMSHA) as an evidence-based approach in caring for emergency room patients. TIC interventions include creating a coercive and violence free environment, empowering voice, providing respect and transparency, making connections, creating comfortable spaces, and offering hope for recovery [7].

\section{Rationale}

Effectiveness was chosen from the Institute of Medicine's 6 Domains of Health Care Quality to determine if TIC could be used to improve healthcare of behavioral health patients [8]. The framework for studying this problem was based on the Kotter Change Model (gold standard), which was conceived in 1996 to improve an organization's ability to change (see Appendix A Kotter's Model) and involves eight steps and four principles [9]. The aim of the study was to implement TIC to improve the effectiveness of pediatric behavioral healthcare in the emergency department by $25 \%$ in 90 days.

\section{Methods}

The quality improvement initiative was conducted in the emergency room of a 152-bed children's hospital located in a large southeastern urban city. The emergency room sees approximately 100 behavioral health patients a month for suicidal ideation. According to electronic medical records most patients $(65.2 \%)$ have Medicaid and are white $(79 \%)$. The behavioral health pod had no designated psychiatric providers with social workers performing psychosocial assessments and referrals. The trauma-informed team consisted of the Director of Care Coordination (sponsor), Director of Quality and Patient Safety (mentor), the Director, Charge Nurse, and Staff Educator, and three social workers of the Emergency Services, and faculty continuity coach. 


\section{Kotter's Change Management Model}

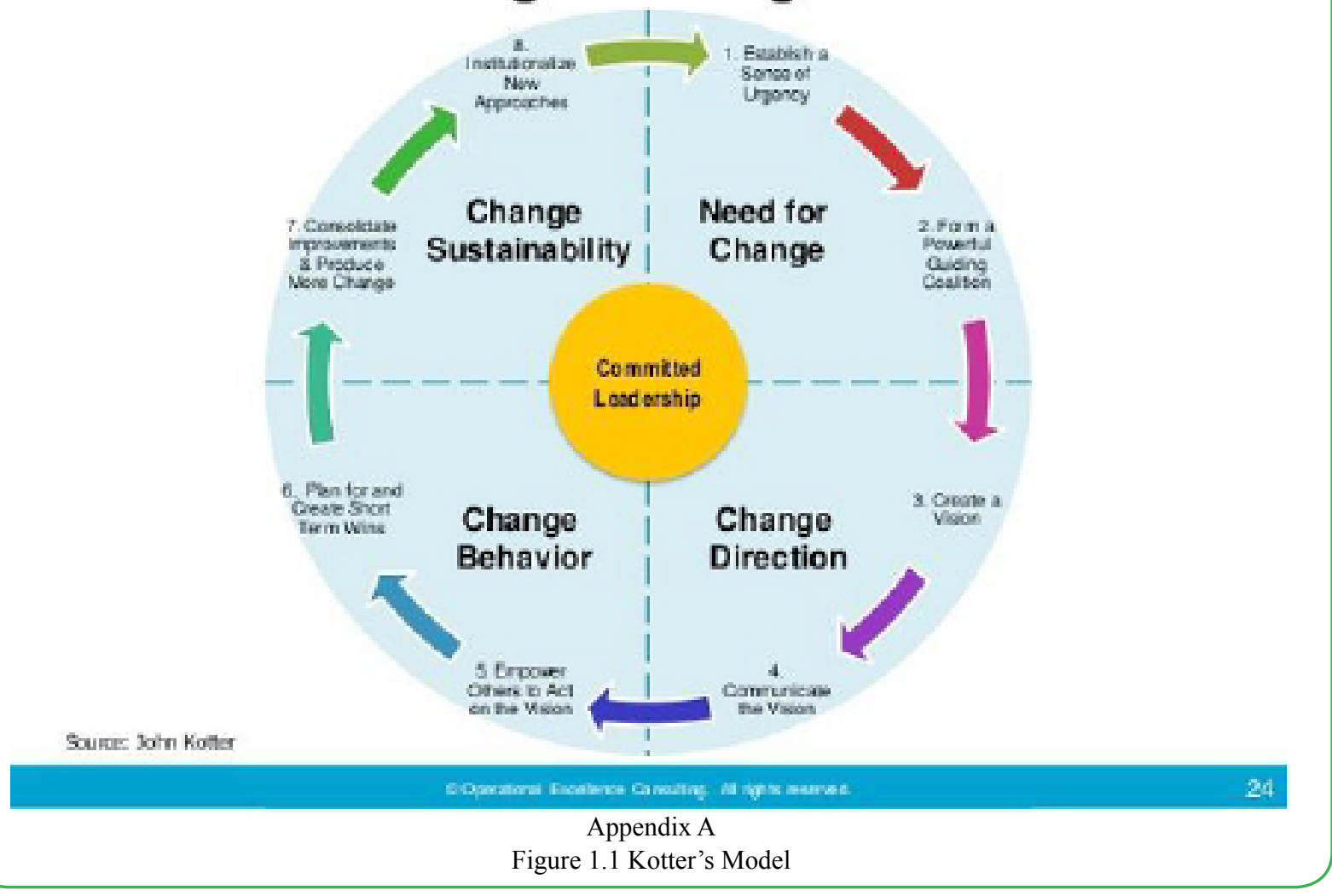

An iterative process (PDSA) was used to deliver four different interventions every 2 weeks for 16 interventions (see Appendix B

Test of Change). The four focus areas were adolescent and guardian screening, chart audits, and a team engagement plan [10].

\begin{tabular}{|c|c|c|c|c|}
\hline Interventions & PDSA cycle 1 & PDSA cycle 2 & PDSA cycle 3 & PDSA cycle 4 \\
\hline $\begin{array}{l}\text { Patient } \\
\text { Engagement }\end{array}$ & \begin{tabular}{|lrr} 
& $H \quad Q \quad-$ & $A$ \\
administration & via \\
paper and crayon
\end{tabular} & $\begin{array}{l}\text { PHQ-A administered } \\
\text { on an I-PAD }\end{array}$ & $\begin{array}{l}\text { Stop PHQ-A screening } \\
\text { in children under age } 11\end{array}$ & $\begin{array}{l}\text { Administer Mood } \\
\text { and Feelings Questi- } \\
\text { onnaire to children } \\
7-11 \text { years of age }\end{array}$ \\
\hline Parent Engagement & $\begin{array}{l}\text { HAM-A verbal } \\
\text { administration }\end{array}$ & $\begin{array}{l}\text { HAM-A tool to be } \\
\text { administered } \\
\text { social workers. }\end{array}$ & $\begin{array}{l}\text { Add discussion of } \\
\text { Guardian Education } \\
\text { Packet with parents by } \\
\text { social workers }\end{array}$ & $\begin{array}{l}\text { Provide brief } \\
\text { supportive therapy } \\
\text { to parents of children } \\
\text { under 11 years of age }\end{array}$ \\
\hline Chart Audit & $\begin{array}{l}\text { Chart Audits done } \\
\text { on six effectiveness } \\
\text { indicators }\end{array}$ & $\begin{array}{l}\text { Chart Audits to add } \\
\text { psychiatric histories. }\end{array}$ & $\begin{array}{l}\text { AddACEs questionnaire } \\
\text { screening, Referral } \\
\text { Manual and Guardian } \\
\text { Education Packet. }\end{array}$ & $\begin{array}{l}\text { Track recidivism and } \\
\text { present policy for } \\
\text { patient follow-up for } \\
\text { repeat offenders }\end{array}$ \\
\hline Team Engagement & $\begin{array}{l}\text { Kickoff Meeting } \\
\text { TIC Bulletin Board } \\
\text { TIC Learning } \\
\text { Module/Exam } \\
\text { Confidence Survey }\end{array}$ & $\begin{array}{l}\text { 1920s event } \\
\text { Professional TIC } \\
\text { signs dispersed } \\
\text { throughout ED }\end{array}$ & $\begin{array}{l}\text { Weekly lottery for } \\
\text { completion TIC } \\
\text { Learning Module, } \\
\text { Mardi Gras event and } \\
\text { Huddle In-services }\end{array}$ & $\begin{array}{l}\text { Place T.I.C. } \\
\text { information in } \\
\text { ETCH newsletter. } \\
\text { Share TIC Toolkit } \\
\text { with T.I.C. Team } \\
\text { Send video on } \\
\text { hospital orientation } \\
\text { to T.I.C. Team }\end{array}$ \\
\hline
\end{tabular}

Appendix B

Table. 1 Test of Change 


\section{Interventions}

The social workers handed the patient a PHQ-A questionnaire (depression screening tool) to fill out themselves or with help of the social worker. The Doctor of Nursing Practice (D.N.P.) student verbally administered the HAM-A (anxiety screening tool) to the guardian in a private room and conducted the chart audits onsite researching rates of recidivism, screening tools, medication, referrals, trauma histories, and guardian education. Multiple team engagement strategies were conducted by the D.N.P. student.

\section{Study of the Interventions}

Both quantitative and qualitative approaches were used to assess the impact of the interventions on outcomes. Run charts on both the process and outcomes of the two screening tools (PHQ-A and HAM-A), chart audits, team engagement, and overall effectiveness were studied every 3 days. Aggregate tables on the results of the PHQ-A, HAM- A, chart audits, and team confidence survey results were studied at the completion of each rapid cycle. Likert scales on the team confidence surveys and qualitative data from the field notes were used to assess progress toward the aim of the study.

\section{Measures}

The interventions used a variety of processes, outcomes, and balancing measure to discern the impact of the quality improvement initiative [11]. The PHQ-A (adapted from the adult version PHQ-9) is a 9-item diagnostic tool that addressed the severity of depressive disorders in children 12-17 years of age. Responses range from 0 (not at all) to 3 (nearly every day) with over 10 indicating depression. Cronbach alphas of .89 were recorded [12]. The HAM-A is a psychological questionnaire used to rate the severity of anxiety. The scale consists of 14 items (symptoms) rated on a scale of zero (not present) to four (severe). Scores over 30 indicatesevere anxiety. The sensitivity is 85.7 and specificity is 63.5 [13]. The team confidence survey (approved by the continuity faculty for construct validity) consisted of five Likert scale questions with scoring from 1-5 with 3 indicating confidence. The balancing measure of length of stay in the hospital was used to determine if the interventions had unintended undesirable consequences. Tools with high validity and reliability were used to measure outcomes.

\section{Analysis and Ethical Considerations}

Data from each tool on aggregate data was evaluated at the end of each test of change for low scores. Run charts were evaluated for shifts (seven or more consecutive points on one side of the median) or trends (seven or more points continually increasing or decreasing). Astronomical data points (a data point that is dramatically different from the rest) on run charts were noted. Qualitative data was evaluated for context, content, and themes. This unfunded 8-week doctoral initiative was excused from review by the Institutional Review Board at Frontier Nursing University because it does not qualify as human subjects research and meets federal requirements for quality improvement.

\section{Results}

Within 90 days, the aim of the study was to improve the effectiveness of pediatric behavioral health care in the emergency department by $25 \%$ through the implementation of trauma informed care. The overall percentage points rose from $54 \%$ to $65.1 \%$, which was a $20.6 \%$ increase but fell short of the goal of $25 \%$. The balancing measure (length of stay) had an end point of 211 , which was less than the goal of 446.6 (see Appendix C Measurement Worksheet).

\begin{tabular}{|c|c|c|c|c|c|}
\hline $\begin{array}{l}\text { TOC/Core Intervention Tool \& } \\
\text { Hyperlink }\end{array}$ & Measure & $\begin{array}{l}\text { Operation a } 1 \\
\text { Definition }\end{array}$ & \begin{tabular}{|l} 
Baseline \\
$\mathrm{n}(\%)$
\end{tabular} & Goal & \begin{tabular}{|ll} 
Overall & Results \\
$\mathrm{n}(\%)$ & \\
\end{tabular} \\
\hline \multicolumn{2}{|c|}{$\begin{array}{l}\text { AIM: Within } 90 \text { days, the effectiveness of pediatric } \\
\text { behavioral emergency healthcare will be improved } \\
\text { by } 25 \% \text { through the implementation of trauma } \\
\text { informed care. }\end{array}$} & 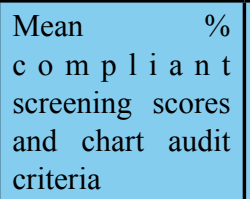 & $95(54)$ & $68 \%$ & $232(65.1)$ \\
\hline $\begin{array}{l}\text { PHQ-9 Modified for } \\
\underline{\text { Adolescents }}\end{array}$ & Process & 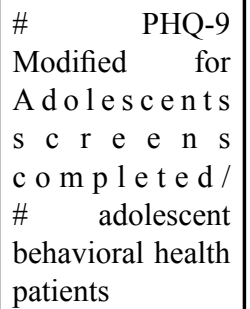 & $0(0)$ & $75 \%$ & $51(57)$ \\
\hline $\begin{array}{l}\text { Scoring Modified PHQ-9 } \\
\text { Mood and Feelings } \\
\text { Questionnaire }\end{array}$ & Outcome & $\begin{array}{l}\# \text { adolescents } \\
\text { who } \text { screened } \\
\text { negative }(<10) \\
\text { for depression } \\
\text { I\# adolescents } \\
\text { screened }\end{array}$ & $11(0)$ & $75 \%$ & $1(.01)$ \\
\hline \multirow[t]{2}{*}{ HAM-A Parent Screening } & Process & 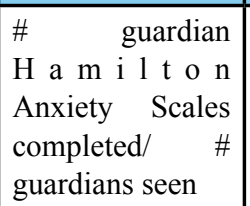 & $0(0)$ & $75 \%$ & $48(54)$ \\
\hline & Outcome & $\begin{array}{|lr|}\# & \text { screened } \\
\text { negative } & (<30) \\
\text { for } & \text { severe } \\
\text { anxiety/ } & \# \\
\text { guardians } & \text { seen } \\
\end{array}$ & $12(100)$ & $75 \%$ & $48(95.8)$ \\
\hline
\end{tabular}

Table. 2 to be Cont........... 


\begin{tabular}{|c|c|c|c|c|c|}
\hline \multirow[t]{2}{*}{ Chart Audits } & Process & 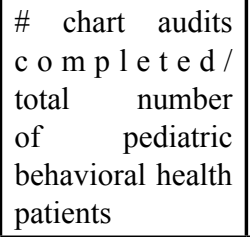 & $0(0)$ & $75 \%$ & $89(100)$ \\
\hline & Outcome & 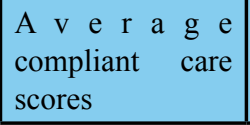 & $27(43)$ & $75 \%$ & $89(64.8)$ \\
\hline \multirow[t]{2}{*}{$\begin{array}{l}\text { Team Engagement Plan } \\
\text { Team Engagement-Final.docx } \\
\text { Team Confidence Outcome } \\
\underline{\text { Survey final.docx }}\end{array}$} & Process & \begin{tabular}{|lr}
$\#$ & team \\
e n g a g e m e n t & \\
encounters/ $\#$ \\
team engagement \\
e n c o u n t e r s \\
scheduled
\end{tabular} & $0(0)$ & $75 \%$ & $15(91.8)$ \\
\hline & Outcome & $\begin{array}{l}\text { A } v \text { e } r \text { a } g \text { e } \\
c \text { o } n \text { fi } d \text { e } n \text { c e } \\
\text { scores }\end{array}$ & $11(91)$ & $75 \%$ & $45(100)$ \\
\hline \multicolumn{2}{|c|}{$\begin{array}{l}\text { Balancing Measure: The length of stay should not } \\
\text { increase by more than } 10 \% \text { due to trauma-informed } \\
\text { healthcare interventions. }\end{array}$} & $\begin{array}{l}\text { Average length } \\
\text { of stay }\end{array}$ & $406^{1}$ & $<446.6^{1}$ & 585.9 \\
\hline
\end{tabular}

Appendix C

Table. 2 Measurement Worksheet

\begin{tabular}{|l|l|l|l|l|l|}
\hline \multirow{4}{*}{ Indicator } & PDSA 1 & PDSA 2 & PDSA 3 & PDSA 4 & PDSA 5 \\
\cline { 2 - 6 } & $\mathrm{N}=13$ & $\mathrm{~N}=27$ & $\mathrm{~N}=28$ & $\mathrm{~N}=23$ & $\mathrm{~N}=89$ \\
\cline { 2 - 6 } & Mean n (\%) & Mean n (\%) & Mean n (\%) & Mean n (\%) & Mean n (\%) \\
\hline Recidivism & $11(88)$ & $20(73)$ & $20(77)$ & $17(72)$ & $69(77.5)$ \\
\hline Trauma History & $3(22)$ & $14(51)$ & $11(42)$ & $11(46)$ & $36(40.25$ \\
\hline Screening Tools & $13(100)$ & $4(15)$ & $16(62)$ & $16(70)$ & $55(61.75)$ \\
\hline Medication & $9(66)$ & $27(100)$ & $21(81)$ & $18(77)$ & $72(81)$ \\
\hline $\begin{array}{l}\text { Patient/Family } \\
\text { Education }\end{array}$ & $0(0)$ & $13(49)$ & $20(77)$ & $17(76)$ & $45(50.5)$ \\
\hline Referral & $9(66)$ & $20(73)$ & $19(73)$ & $23(100)$ & $69(78)$ \\
\hline $\begin{array}{l}\text { P s y c h i a tr i c } \\
\text { History }\end{array}$ & & & & $7(32)$ & $7(32)$ \\
\hline
\end{tabular}

Appendix D

Table. 3 Chart Audit Effectiveness

\section{PHQ-A Intervention.}

Fifty-one patients were screened by the social workers using the PHQ-A tool via paper and crayon with $100 \%$ noncompliance (Cycle 1). Because adolescents are more likely to answer honestly by computer, the PHQ-As were given to 11 patients by computer, which also led to no change in the non-compliance rate of $100 \%$ (Cycle 2). An influx of younger children (PHQ-A approved for 12 and older) caused the substitution of tools to the Mood and Feelings Questionnaire for children under 12 years of age [14]. A 13-item questionnaire with a scale of $0-2$ with 11 indicating depression has .84 reliability and .73 validity. At that time, the baseline of noncompliance for 15 patients decreased to $66 \%-80 \%$ (Cycle 3). Fourteen patients were screened with the Mood and Feelings Questionnaire which lead to an increase of noncompliance of $100 \%$ (Cycle 4). There were two runs in the process and outcome charts and a shift of six data points in the screening run chart below the median but no trends. The shifts also contained a couple of astronomical data points illustrating that children under 12 were not depressed but angry.

\section{Hamilton Anxiety Scale Intervention}

Forty-eight guardians were verbally screened by the D.N.P. student using the Hamilton Anxiety Scale (HAM-A) with $100 \%$ compliance (Cycle 1). Due to erratic presence of guardians the social workers began administering the HAM-A, which increased the number being screened (Cycle 2). Around the fifth week younger children were admitted, and the rate dropped to $50 \%$ compliance. It was discovered that only guardians of children going home were given safety education, which prompted the development of a guardian education packet for all children (Cycle 3). Because the HAM-A scores of parents of younger children were dramatically elevated, it was decided to provide brief supportive therapy to guardians prior to their filling out the HAM-A Questionnaire [15]. This led to a return to $100 \%$ compliance scores (Cycle 4 ). There was great variability in the number of screenings on the run charts (10 runs) because of guardian inaccessibility. An astronomical data point was seen in the outcomes run chart of guardians of younger children as their anxiety levels rose out of compliance. There were three runs on the outcome run chart but no shifts or trends evident.

\section{Chart Audit Intervention}

Eighty-nine charts were audited by the D.N.P. student on six effectiveness measures (recidivism, medication administration, 
parental education, trauma history, referrals, and screening tools) and length of stay as a balancing measure. Compliance increased from $20 \%$ to $57 \%$. (Cycle 1). Due to no full-time psychiatrist few psychiatric histories were completed so psychiatric histories were added to the chart audits. This led to a drop in compliance from $80 \%$ to $50 \%$ (Cycle 2). To improve screening for trauma the ACE questionnaire, a 10-item tool with a score of 4 indicating a risk for health and social problems was added [16]. A referral manual was developed to facilitate the referral process. The change in this cycle resulted in an eventual increase up to $90 \%$ (Cycle 3 ). To improve the recidivism (readmission in 30 days) rate a policy for patient follow up was developed and was the most impactful intervention (Polits, 2016). The compliance rates for this cycle then finished with an $85.5 \%$ (Cycle 4). There was one run on the process run chart and five runs on the outcome run chart, but there were no shifts or trends (see Appendix D Chart Audit Effectiveness).

\section{Team Engagement Intervention}

To promote team participation a T.I.C. Bulletin Board was placed in a busy hallway with ongoing contest questions added and a hospital wide T.I.C. learning module developed. Team confidence was at the $56 \%-80 \%$ (Cycle 1). To increase participation and scores a 1920s event was held along with T.I.C. sign displays. The number of participants doubled, and the scores rose to $100 \%$ (Cycle 2).
To maintain interest a Mardi Gras event was held, a lottery for completion of the T.I.C. learning module conducted, and huddles provided for team education about behavioral health care (Cycle 3). For sustainability of the initiative a T.I.C. Toolkit and a video promoting hospital wide orientation was sent to the TIC Team and proved to be the most significant intervention. [17]. The final team of 17 had a $100 \%$ confidence rate (Cycle 4 ). There were two runs and one astronomical data point on the team process run chart. There were six or more data points above the median on the outcome run chart which is found in shifts. The number of team confidence surveys completed rose steadily, but no shifts or trends were visible.

\section{Discussion}

The aim of the initiative, to improve the effectiveness of pediatric behavioral healthcare in the emergency room, achieved $65.1 \%$ of the goal (68\%) (see Appendix E Effectiveness Run Chart). Regarding questions, predictions, and analysis of data it was a surprise to see the difference between PHQ-A and HAM-A scores, to realize how important chart audits and trending can be to find root causes of problems, to learn the need for knowledge and consistent coverage of behavioral health in the emergency room, and to see how evidence based practice and safety is so important. Team engagement was the greatest strength of this project.

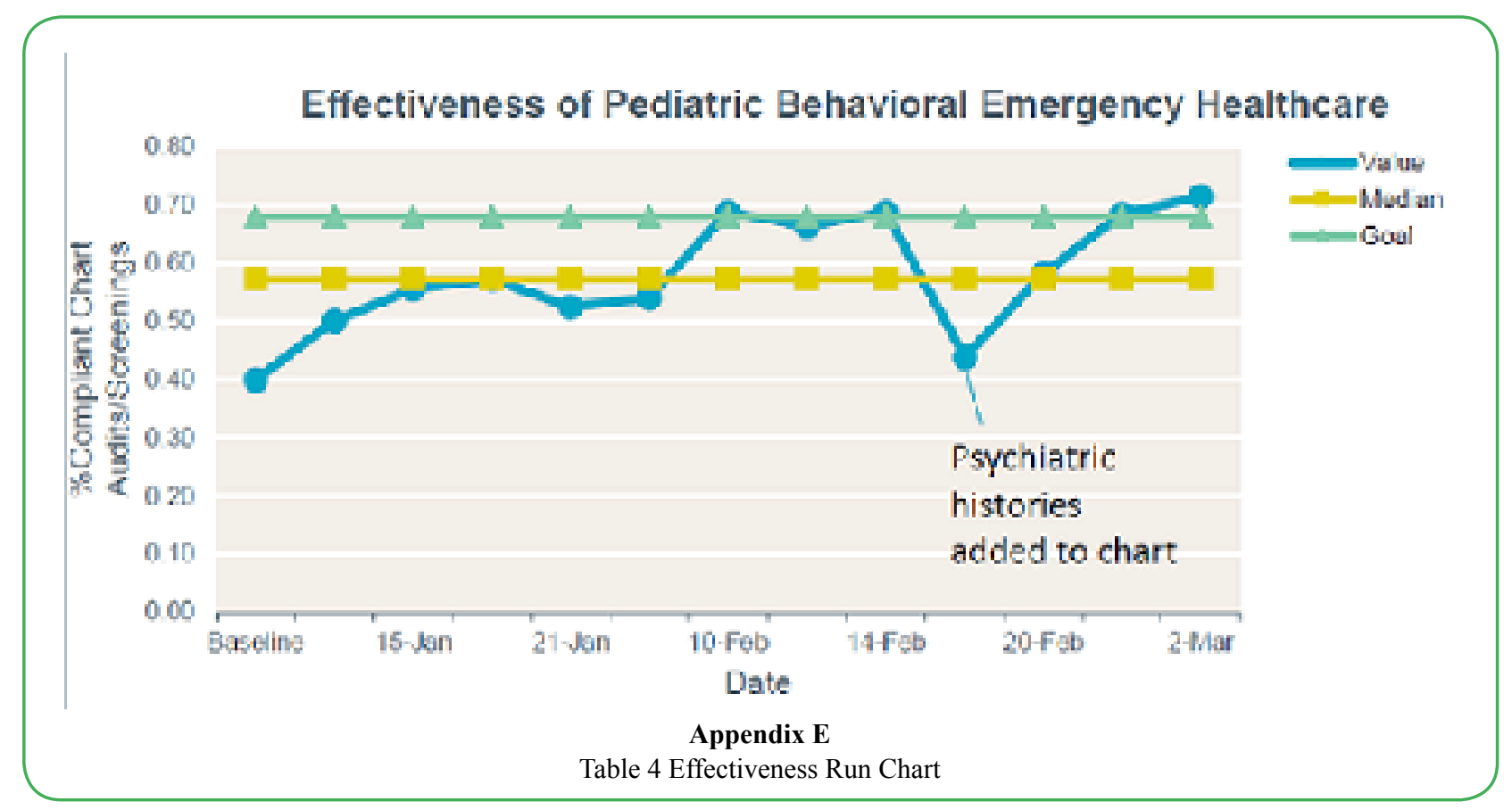

\section{Interpretation}

Changes on depression and anxiety scores on the PHQ-A and HAM-A could not be causally linked to the implementation of TIC but likely due to patient age. The addition of brief supportive therapy to guardians of young patients seemed to correlate with decreased anxiety scores[18]. Because of the iterative changes in screening tools it was not possible to show long-term trends. However, some of the chart audit element interventions (referrals, guardian education, medical administration, and trauma histories) could be said to show an upward trend. Length of stay decreased, probably due to the increased availability of patient rooms rather than TIC. The success of the project centered around the TIC team's support of the initiative. Engagement strategies positively impacted TIC knowledge levels of staff as validated by a report by Samhsa (2020) despite staff stress[19] and provided TIC care to the overwhelmed staff. Not being an employee gave a fresh perspective but left only persuasive power and no legitimate authority to implement interventions.
Barriers to implementation included an ongoing construction project, staff stress due to lack of patient rooms and protocol changes, limited contact with patients and staff, no office space, limited social worker contact with all patients and guardians, and the fact that different providers saw the behavioral health patients. Continuity of care as a standard of quality could be improved [20]. Standardized screening identified patients at risk.

\section{Limitations}

The small sample size affected both internal and external validity and the fact that patients seen by Mobile Crisis and the psychiatrist were inconsistently included in the study could have resulted in selection bias. The lack of consistent behavioral health providers made for inconsistency in huddle educational sessions. The D.N.P. student was restricted from having any contact with the staff or patients due to ongoing major construction in the emergency room. This was attempted to be mitigated with continuous educational events and narrated online modules. Unfortunately, it was not possible to match the surveys from patients and guardians due to 
erratic guardian presence. The length of stay did not consider if the patient was being referred to inpatient versus outpatient. This initiative would be most successful where the student has access to staff and there are consistent behavioral health providers.

\section{Conclusions}

It cannot be said definitively that TIC improved the effectiveness of pediatric behavioral healthcare in this emergency room, but there were several indications that the upward trend of selected measures (overall effectiveness of pediatric behavioral healthcare, specific chart audit elements (recidivism, trauma history, medication administration, family education, referrals, confidence team scores, and length of stay) might have continued [21].

This project is sustainable due to the administrative support I witnessed during the project implementation. The addition of hospital-wide assessment of a patient's depression, anxiety, and trauma histories support psychiatric measurement-based care and TIC. Further steps would be to incorporate TIC information in hospital-wide employee orientations and to include TIC as part of the guiding principles and overarching documents of the institution.

Conflicts of interest/Competing interests: Authors report no conflict or competing interest.

\section{References}

1. Bonn, S. (2019). Suicide rates, even among children, are rising dramatically. Psychology Today. Retrieved from https://www. psychologytoday.com/us/blog/wickeddeeds/20191/suiciderates-even-among-children-are-rising-dramatically

2. National Center for Health Statistics (2019). Death Rates Due to Suicide and Homicide Among Persons Aged 10-24: United States, 2000-2017. (NCHS Data Brief No 352) Atlanta, GA: Curtin, S. \& Heron, M

3. Suicide Prevention Center (2019). Number of children going to ER with suicidal thoughts, attempts, Doubles, study finds. Retrieved from https://www.sprc.org/news/number-childrengoing-er-suicidal-thoughts-attempts-doubles-study-finds

4. Franklin, S. (2018). East Tenn. Children's Hospital: Teens with suicidal thoughts have doubled. Retrieved from https://www. wbir.com/article/news/local/east-tenn-childrens-hospital-teenswith-suicidal-1 thoughts-have-doubled/51-553183781

5. Viner, B. (2005). Using audit to improve clinical effectiveness. https://inpractice.bmj.com/content/31/5/240

6. Attaway, J. (2019). Taking a child to the emergency room. Retrieved from https://childmind.org/article/taking-a-child-tothe-emergency-room/

7. Samhsa-HRSA (2020). Brief Interventions. Retrieved from https://www.integration.samhsa.gov/clinical-practice/sbirt/ brief-interventions

8. Agency for Healthcare Research and Quality (2018). Six domains of health care quality. Retrieved from https://www. ahrq.gov/talkingquality/measures/six-domains.html

9. Bolman, L. \& Deal, T. (2017). Reframing Organizations. Hoboken, New Jersey: John Wiley \& Sons

10. Institute for Health Improvement (2017). Tools: Plan-DoStudy-Act (PDSA) Worksheet. Retrieved from http://www.ihi. org/resources/Pages/Tools/PlanDoStudyActWorksheet.aspx

11. American Academy of Child and Adolescent Psychiatry (2019). Toolbox of Forms. Retrieved from https://www.aacap.org/ AACAP/Member_Resources/AACAP_Toolbox_for_Clinical_ Practice_and_Outcomes/Forms.aspx

12. American Psychological Association (2020). Patient Health Questionnaire (PHQ-9 \& PHQ-A). Retrieved from https://www. apa.org/pi/about/publications/caregivers/practice-settings/ assessment/tools/patient-health
13. Psychiatry \& Behavioral Health Learning Network (2020). Hamilton Anxiety Rating Scale (HAM-A). Retrieved from https://www.psychcongress.com/saundras-corner/scales screeners/anxietdisorders/hamilton-anxiety-rating-scale-ham

14. Child Outcomes Research Consortium (2020). Mood and Feelings Questionnaire (MFQ). Retrieved from https://www. corc.uk.net/outcome-experience-measures/mood-and-feelingsquestionnaire/

15. National Alliance on Mental Illness (2019). Family Education and Support. Retrieved from https://www.nami.org/LearnMore/Mental-Health-Public-Policy/Family-Education-and Support

16. American Academy of Pediatrics (2020). Clinical Assessment Tools. Retrieved from https://www.aap.org/en-us/advocacyand-policy/aap-health-initiatives/resilience/Pages/ClinicalAssessment-Tools.aspx

17. Crisis Prevention Institute (2017). Trauma-Informed Care Resources Guide. Retrieved from https://thecenterofhope. org/wp-content/uploads/2019/10/Trauma-Informed-CareResources-Guide-CPI.pdf

18. Rothe, E. (2017). Supportive psychotherapy in everyday clinical practice: It's like riding a bicycle. Psychiatric Times, 34(5), 1-3.

19. Vogel, S., Kluen, L., Fernandez, G., \& Schwabe, L. (2018). Stress affects the neural Ensemble for integrating new information and prior knowledge. Neuroimage, 173 176-187.

20. American Academy of Family Physicians (2020). Continuity of Care. Retrieved from https://www.aafp.org/about/policies/all/ definition-care.html

21. Harborview Injury Prevention Center (2017). Growing body of research indicates trauma care, Suicide prevention go handin-hand. Retrieved from https://depts.washington.edu/hiprc/ growing-body-of-research-indicates-trauma-care-suicideprevention-go-hand-in-hand 